\title{
Clinical analysis of ectopic pregnancies in Majmaah, Saudi Arabia.
}

\author{
Hussam Zain ${ }^{1}$, Rayan G Albarakati ${ }^{1}$, Yousif M.Y. Abdallah ${ }^{2 *}$, Almuteri,tayseer dhayfallah ${ }^{1}$, Sami Elgak $^{2}$, Elsadig \\ Yousif Mohamed $^{3}$, Elabbas M. Ebaid ${ }^{4}$ \\ ${ }^{1}$ Department of Obstetrics and Gynecology, College of Medicine, Majmaah University, Majmaah, 11952, Saudi Arabia \\ ${ }^{2}$ Department of Radiological Science and Medical Imaging, College of Applied Medical Science, 11952, Majmaah University, Saudi Arabia \\ ${ }^{3}$ Department of Society Medicine and Health, College of Medicine, Majmaah University, Majmaah, 11952, Saudi Arabia \\ ${ }^{4}$ Department of Radiology, College of Medicine, Majmaah University, Majmaah, 11952, Saudi Arabia
}

\begin{abstract}
Ectopic Pregnancy (EP) is a serious emergency faced by physicians in obstetrics and gynaecology, and the identification of EP can be frequently missed. The common signs of ectopic pregnancy in fertile women are lower abdominal discomfort and vaginal hemorrhage. The aim of this paper was to study EP patients to determine the etiology and management of EP. This study aims to study the hazardous factors, types, and clinical complications associated with EP patients, as well as diagnostic methods and prognosis. This was a retrospective cohort study performed at King Khalid Hospital, Majmaah, Saudi Arabia. Patient demographic data were documented. These data included parity, hazardous factors, signs and symptoms, habits, occupation, past history of PID, ectopic pregnancy, pelvic surgery and management. The data were analyzed using statistical software in MS Windows. The data are presented as the mean plus standard deviation. In our study, most cases $(83.3 \%)$ were managed surgically, which means that too few cases were given medical or conservative options; thus, medical staff training in how to apply medical or conservative management techniques according to guideline criteria can improve future outcomes.
\end{abstract}

Keywords: Clinical, Ectopic, Pregnancies, Saudi Arabia.

Accepted on April 23, 2019

\section{Introduction}

Ectopic pregnancy is a gynaecological emergency that increases maternal mortality and morbidity, and a great deal of effort should be made for early diagnosis and treatment to reduce the mortality caused by ectopic pregnancy [1-3]. The most common presentation is classic symptoms of vaginal bleeding and abdominal pain, which can be described as sharp, dull or cramping. Bleeding into the peritoneum causes irritation, which results in shoulder tip pain [4-6]. Risk factors for ectopic pregnancy include pelvic inflammatory disease, smoking, pelvic surgery, past history of infertility and recent use of assisted reproductive techniques [7-9]. Most cases of ectopic pregnancy occur in a Fallopian tube; tubal pregnancy occurs in more than $90 \%$ of ectopic pregnancies, and less frequent sites include the cervix, ovary, and abdominal cavity [10-13]. The incidence of an ectopic pregnancy is approximately $1 \%$ to $2 \%$, and it can reach $4 \%$ when assisted reproductive techniques are used. The medical signs of ectopic pregnancy usually occur between 4 weeks and 8 weeks, depending on the site of implantation. Many hazardous factors are associated with ectopic pregnancy. Reducing these factors can result in a decrease in incidence, but more than $30 \%$ of cases occur without risk factors. In normal pregnancy after fertilization, the embryo is advanced toward the uterus by the action of the cilia that are located in the tube; any factor, such as smoking, can lead to damage of the cilia, preventing the passage of the embryo from the tube to the uterus [14-16]. Women with PID have a higher risk for ectopic pregnancy because organisms, such as chlamydia and gonorrhea, can cause damage to the cilia and scar formation, which leads to a blockage of the tube [17-19]. Other factors, such as Asherman syndrome, the reversal of tubal ligation and a history of ectopic pregnancy, are also risk factors for EP. The diagnosis of ectopic pregnancy requires high clinical suspicion for any woman who presents with lower abdominal pain and vaginal bleeding; symptoms and signs should be followed by blood tests for BHCG and ultrasonography examination. Ultrasound has $90 \%$ accuracy in the detection of ectopic conditions [20]. Ectopic pregnancy is usually diagnosed as an adnexal bulky mass of the ovary [21]. The idea is to find an empty uterus in a patient with an adnexal mass and a positive pregnancy test. Both pregnancy checks and heterotopic pregnancy "pseudosacs" are detected in $20 \%$ of women [22]. Other diagnostic methods include laparoscopy and laparotomy, which are reserved for acute cases that are complicated by hypotension and have visual confirmation of the diagnosis. Some anomalies, such as miscarriage, ovarian torsion, ovarian cysts, acute appendicitis, kidney stones and pelvic inflammatory disease, have the same signs as an ectopic pregnancy. The management of ectopic pregnancy depends on the presentation of the patient. There are many choices for the management of EP, such as expectant management, in which the provider needs to follow the TVS and BHCG levels of the patient until the patent recovers completely; however, in this type of management, the patent must fulfill certain criteria, such as hemodynamic stability, a low concentration of BHCG, a small mass and no cardiac activity [23]. Early treatment for ectopic pregnancy with 
methotrexate is a viable alternative. If administered early during pregnancy, methotrexate ends the development of the emerging embryo. This approach causes an abortion, and an emerging embryo may later be removed by the body or menstruation. This approach should not be used in women who have liver, kidney, or blood illnesses or in women with an ectopic embryonic mass $>3.5 \mathrm{~cm}$. When the patient experiences bleeding, an emergency surgery should be performed. Nevertheless, it is a difficult decision in steady patients with no evidence of a blood clot on an ultrasound. Laparotomy is used to cut pretentious Fallopian tubes and to remove ectopic pregnancies [24]. Complications of ectopic pregnancy usually result from the rupture of the tube and hemoperitoneum with hypovolemic shock that leads to death [25].

\section{Material and Methods}

Patient characteristics, such as age, parity, presentation signs and symptoms, past history of PID, ectopic pregnancy and pelvic surgery, were documented. For statistical analysis, a computer-supported program was used.

\section{Results}

The results are mentioned in the table (Table 1-7).

Table 1. Patient characteristics.

\begin{tabular}{lc}
\hline Characteristics & $\%$ \\
\hline Age (Mean=29.67 \pm 6.06; 18-42years) & 62.8 \\
\hline $21-30$ years & 34.9 \\
\hline $31-40$ years & 2.3 \\
\hline$>40$ years & \\
\hline Occupations & 2.7 \\
\hline House wife & 51.4 \\
\hline Student & 40.3 \\
\hline Employer & \\
\hline
\end{tabular}

\begin{tabular}{|c|c|}
\hline Labor & 5.6 \\
\hline \multicolumn{2}{|l|}{ Parity } \\
\hline 1 & 67.4 \\
\hline 43500 & 25.6 \\
\hline$>4$ & 7 \\
\hline \multicolumn{2}{|l|}{ Risk factors } \\
\hline History of abortions ( $\geq 1$ ) & 0 \\
\hline History of previous ectopic pregnancy & 4.7 \\
\hline History of pelvic surgery & 2.3 \\
\hline History of infertility & 7 \\
\hline History of PID & 9.3 \\
\hline History of intrauterine contraceptive device & 23.3 \\
\hline \multicolumn{2}{|l|}{ Smoking } \\
\hline Active & 2.4 \\
\hline Non-smokers & 97.6 \\
\hline \multicolumn{2}{|l|}{ Signs } \\
\hline Haemodynamic shock & 26.4 \\
\hline Abdominal tenderness & 75 \\
\hline Cervical motion tenderness & 58.3 \\
\hline \multicolumn{2}{|l|}{ Complications } \\
\hline Infections & 4.7 \\
\hline Transfusion & 41.9 \\
\hline Re-admission & 18.6 \\
\hline Other & 34.9 \\
\hline \multicolumn{2}{|l|}{ Counselling about ectopic pregnancy } \\
\hline Received & 36.6 \\
\hline Not received & 64.4 \\
\hline
\end{tabular}

Table 2. Risk factors for ectopic pregnancy.

\begin{tabular}{|c|c|c|c|c|c|c|c|c|}
\hline \multirow{2}{*}{ Factors } & \multicolumn{8}{|c|}{ OR ( and $95 \% \mathrm{CL}$ ) } \\
\hline & $\begin{array}{l}\text { Present } \\
\text { Study }\end{array}$ & Mehta et al. [11] & $\begin{array}{l}\text { Mol et al. } \\
{[11]}\end{array}$ & $\begin{array}{l}\text { Dart et al. } \\
\text { [13] }\end{array}$ & $\begin{array}{l}\text { Maka et al. } \\
{[23]}\end{array}$ & $\begin{array}{l}\text { Samiya et al. } \\
\text { [9] }\end{array}$ & $\begin{array}{l}\text { Shetty et al. } \\
\text { [9] }\end{array}$ & Kendrick et al. [17] \\
\hline $\begin{array}{l}\text { Previous } \\
\text { surgery }\end{array}$ & 2.3 & 21 & - & - & 4 & - & 3.2 & - \\
\hline $\begin{array}{l}\text { Previous } \\
\text { pregnancy }\end{array}$ & 4.7 & 8.3 & - & - & - & 5.2 & 3.2 & 8.3 \\
\hline History of PID & 9.3 & 2.5 & - & - & 2 & 10 & 3.2 & 15.8 \\
\hline History of infertility & 7.0 & $2.5-21^{*}$ & - & 5.0 & 16 & 8.8 & 3.2 & 7.0 \\
\hline Tubal ligation & - & - & 9.3 & 18 & 4 & - & - & 6.2 \\
\hline
\end{tabular}


Clinical analysis of ectopic pregnancies in Majmaah, Saudi Arabia

\begin{tabular}{|c|c|c|c|c|c|c|c|}
\hline Current IUD use & & $4.2-45^{*}$ & 5.0 & 6 & - & 6.4 & 6.6 \\
\hline \multicolumn{4}{|c|}{ Table 3. Risk factors for ectopic pregnancy } & Conservative & 2.4 & - & - \\
\hline Authors & Year & Incidence & & Medical & 14.3 & - & 6 \\
\hline Shetty et al. [9] & 2014 & 5:6 1000 delivers & & Surgical & 83.3 & 100 & 94 \\
\hline Mehta et al. [11] & 2016 & $30: 21000$ delivers & & & & & \\
\hline Present study & 2017 & $12: 11000$ delivers & & & & & \\
\hline
\end{tabular}

Table 4. Management of ectopic pregnancy compared with other authors.

Procedure Present study Mehta et al. [11] Maka et al. [23]

Table 5. Surgical management of ectopic pregnancy compared with other authors.

\begin{tabular}{|c|c|c|c|}
\hline Surgical procedure & Present study & Mehta et al. [11] & Maka et al. [23] \\
\hline Open Salpingectomy & 58.5 & 51.25 & 64 \\
\hline Lap. Salpingectomy & - & 1.25 & 8 \\
\hline Open Salpingectomy with contralateral tubectomy & - & 35 & 14 \\
\hline Salpingostomy & 7.3 & 3.75 & - \\
\hline Salpingo-ophorectomy & 2.5 & 2.5 & 4 \\
\hline Partial oophorectomy & - & 1.25 & - \\
\hline Medical treatment & 14.3 & 2.5 & 6 \\
\hline Partial salpingectomy & - & 1.25 & - \\
\hline Milking & - & 1.25 & - \\
\hline
\end{tabular}

Table 6. Gravida of ectopic pregnancy compared with other authors.

\begin{tabular}{|c|c|c|c|c|c|}
\hline & Present study & Maka et al. [23] & Porwal et al. [5] & Samiya et al. [9] & Maka et al. [23] \\
\hline G1 & 67.4 & 28 & 40 & 53 & 18.4 \\
\hline G2 & 8.5 & 26 & 20 & 29 & 32.5 \\
\hline G3 & 8.5 & 26 & 31.5 & 10 & 43.0 \\
\hline G4 & 8.5 & 18 & 7.5 & 3.5 & 6.1 \\
\hline G6 & 7.0 & 2 & - & 2.63 & - \\
\hline
\end{tabular}

Table 7. Patients clinical presentation.

\begin{tabular}{llll}
\hline Clinical presentation & Present study \% & Leveno et al. [4] & Shetty A et al. [9] \\
\hline Vaginal bleeding & 58.2 & 43.2 & 61.3 \\
\hline Abdominal pain & 86.1 & 89.2 & 80.6 \\
\hline Abdominal tenderness & 75 & 70.3 & 48.4 \\
\hline Cervical tenderness & 58.3 & 75.7 & 51.6 \\
\hline
\end{tabular}




\section{Discussion}

The incidence of ectopic pregnancy in our study was 12 for every 1000 deliveries, which is considered less than international figures, as in the Mehta et al. study [11] performed in 2016, which found that the incidence was 30.2 for every 1000 deliveries. Most of the patients (62.8\%) in our study group fell in to the age group of 21-30 years, which is close to the studies performed by Samiya [9] (75.4\%), Panchal et al. [25]. The minority of patients $(2.3 \%)$ was in the 40 years or older age group, which is similar to most studies because of the general fertility decline with age. In our study, most of the patients were primigravida $(67.4 \%)$, followed by $8.5 \%$ for gravida 2,3 , and 4 as well as $7 \%$ for gravida 6 . This result is similar to the studies performed by Samiya et al. [9] (53\%) and Porwal et al. [5] (40\%). In another study performed by Sudha et al. [24], the majority of patients (81.58\%) were multigravidas, most likely due to previous infection resulting in tubal adhesion and damage. In the present study, $23.3 \%$ of the women had an IUCD in place, which can be considered a strong risk factor for ectopic pregnancy. This result is different from the studies performed by Maka et al. [23] and by Shetty et al. [9], in which $12 \%$ and $6.4 \%$ of the cases with ectopic pregnancy had an IUCD, respectively. In this area of study, IUCDs are the most popular means of contraception. In this study, $9.3 \%$ of the women had a history of pelvic inflammatory disease, which is quite similar to the study performed by Samiya et al. [9] (10\%) and slightly different from the study performed by Maka et al. [23] (2\%). Pelvic infection usually causes damage to the cilia in the tube, which interferes with transport and traps the fertilized ovum, resulting in an ectopic pregnancy. In our study group, $7 \%$ of the women with ectopic pregnancy were infertile, which is similar to the studies performed by Sudha et al. [24] (7.01\%) and Mufti et al. [9] $(8.77 \%)$. The association between infertility and ectopic pregnancy requires further study to find a logical explanation. A history of previous ectopic pregnancy was noted in $4.7 \%$ of women in our study, which correlates with a similar study performed by Samiya et al. [9] (5.2\%) and Shetty et al. [9] $(3.2 \%)$. This is most likely due to tubal factors that are usually bilateral; in some cases, having a history of ectopic pregnancy increases the chance to have another ectopic pregnancy by $17 \%$. The common presenting complaints were abdominal pain and slight vaginal bleeding with clinical signs of abdominal tenderness in addition to cervical motion tenderness. In our study, $58.2 \%$ of patients presented with vaginal bleeding, and $86.1 \%$ of patients presented with abdominal pain, which were similar to the results of a study performed by Shetty et al. [9] (vaginal bleeding (61.3\%) and abdominal pain (80.6\%)). Clinical signs included abdominal and cervical tenderness. In the present study, the majority of patients $(83.3 \%)$ were managed surgically, which was similar to the study performed by Mehta et al. [11] (100\%) and Maka et al. [23] (94\%). Regarding the details of surgery in our study, most surgically managed patients $(58.5 \%)$ had unilateral salpingectomy by laparotomy, which is similar to findings by Mehta et al. [11] $(51.25 \%)$ and Maka et al. [23] (64\%). In the present study, $7.3 \%$ of patients underwent salpingostomy compared to $3.75 \%$ of patients in the Mehta et al. study [11]. Systemic methotrexate was given to $14.3 \%$ of women in our study compared to $6 \%$ of patients in the study performed by Maka et al. [23].

\section{Conclusion}

The incidence of ectopic pregnancy in Saudi Arabia is similar to the rate in developing countries $(1 \%$ to $2 \%)$. This incidence can be reduced by working on preventable risk factors, such as patient education about how to prevent pelvic infections and the use of alternative contraception other than IUCDs; as evident in our study, $23.3 \%$ of patients were using an IUCD. In our study, most patients $(83.3 \%)$ were managed surgically, which means that too few cases are given medical or conservative options; therefore, medical staff training in how to apply medical or conservative management techniques according to guideline criteria can improve future outcomes.

\section{Conflict of Interest}

No potential conflict of interest relevant to this article was reported.

\section{Ethical Approval}

The Institutional Ethics Committee approved the study. [IRB registration KACST, KSA (1439-1073225)].

\section{References}

1. Devi YS. Laparoscopic treatment of ectopic pregnancy. J Obstet Gynecol 2000; 50:69.

2. Rose J, Thomas A, Mhaskar A. Ectopic pregnancy: Five years experience. J Obstet Gynecol 2002; 52:55-58.

3. Mufti S, Rather S, Mufti S, Rangrez RA, Wasiqa K. Ectopic pregnancy: An analysis of 114 cases. JK Pract 2012; 17:20-23.

4. Cunningham FG, Leveno KJ, Bloom SL, Spong CY, Dashe JS, Hoffman BL. Williams. Obstetrics. (24th edn.), Mc Graw Hill Education 2014; 377.

5. Gupta R, Porwal S, Swarnkar M, Sharma N, Maheshwari P. Incidence, trends and risk factors for ectopic pregnancies in a tertiary care hospital of Rajasthan. J Pharm Biomed Anal 2012; 16.

6. ICMR task force project. Multicentric case control study of ectopic pregnancy. J Obstet Gynecol 1990; 40:425-430.

7. Centers for Disease Control and Prevention (CDC). Ectopic pregnancy--United States 1990-1992. MMWR 1995; 44:46.

8. Gaddagi RA, Chandrashekhar AP. A clinical study of ectopic pregnancy. J Clin Diag Res 2012; 6:867-869.

9. Shetty S, Samiya A. A clinical study of ectopic pregnancies in a tertiary care hospital of Mangalore India. Innov J Med Health Sci 2014; 4:305-309.

10. Murray H, Baakdah H, Bardell T, Tulandi T. Diagnosis and treatment of ectopic pregnancy. Can Med Asso J 2005; 173:905-912. 
11. Mehta WM, Mol BW, Van der Veen F, Bossuyt PM. Risk factors for ectopic pregnancy: a meta analysis. Fertil Steril 1996; 65:1093-1099.

12. Buckley RG, King KJ, Disney JD, Gorman JD, Klausen JH. History and physical examination to estimate risk of ectopic pregnancy: validation of a clinical prediction model. Ann Emerg Med 1999; 34:589-594.

13. Dart RG, Kaplan B, Varaklis K. Predictive value of history and physical examination in patients with suspected ectopic pregnancy. Ann Emerg Med 1999; 33:283-290.

14. Cheng MC, Wong YM, Rochat RW, Ratnam SS. Sterilisation failures in Singapore an examination of ligation techniques and failure rates. Stud Fam Plann 1977; 8:109-115.

15. Ory HW. Ectopic pregnancy and intrauterine contraceptive devices: new perspectives. The Women's Health Study. Obstet Gynecol 1981; 57:137-144.

16. Coste J, Job-Spira N, Fernandez H, Papiernik E, Spira A. Risk factors for ectopic pregnancy: a case-control study in France, with special focus on infectious factors. Am J Epidemiol 1991; 133:839-849.

17. Kendrick JS, Atrash HK, Strauss LT, Gargiullo PM, Ahn YW. Vaginal douching and the risk of ectopic pregnancy among black women. Am J Obstet Gynecol 1997; 176:991-997.

18. Govindarajan MJ, Rajan R. Heterotopic pregnancy in natural conception. J Hum Reprod Sci 2008; 1:37-38.

19. Cunningham FG, Leveno K, Bloom S, Spong C, Dashe J, Hoffman B, Casey B. Ectopic Pregnancy. Text book of
Williams Obstetrics Multifetal Ectopic Pregnancy. 21st ed 2003:888-889.

20. Stabile I, Grudzinkas JG. Ectopic pregnancy whats new? Progress Obstet Gynecol 1994:281-310.

21. Parry JS. Extrauterine pregnancy: Its causes, species, pathologic anatomy, clinical history, diagnosis, prognosis, and treatment. J Reprod Med 1876; 34:324-338.

22. Östalo $\mathrm{P}$, Cacciatore $\mathrm{B}$, SjÖberg $\mathrm{J}$, KÄÄriÄinen $\mathrm{M}$, Tenhunen A, Stenman UH. Expectant management of ectopic pregnancy. Obstet Gynecol 1992; 80:345-348.

23. Maka SS, Tondare SB, Tondare MB. Risk factors and management of ectopic pregnancy. Int $\mathrm{J}$ Reprod Contracept Obstet Gynecol 2017; 6:3776-3780.

24. Sudha VS, Thangaraj DR. A retrospective study on ectopic pregnancy: a two year study. Int J Reprod Contracept Obstet Gynecol 2016; 5: 4365-4368.

25. Panchal D, Vaishnav G, Solanki K. Study of management in patient with ectopic pregnancy. Natl J Integr Res Med 2011; 2: 91-93.

\section{*Correspondence to}

Yousif Abdallah

Department of Radiological Science and Medical Imaging

College of Applied Medical Science

Majmaah University

Saudi Arabia 